\title{
DETERMINAÇÃo DA CONCENTRAÇÃo DE PACLOBUTRAZOL POR CROMATOGRAFIA LíQUidA DE ALTA EFICIÊNCIA E ESPECTROSCOPIA
}

Fernanda Leitão Vaz, Mônica Lúcia Barros Milfont, Ana Maria Souto-Maior e Ester Ribeiro Gouveia*

Departamento de Antibióticos, Universidade Federal de Pernambuco, Cidade Universitária, 50670-901 Recife - PE, Brasil

Recebido em 4/8/05; aceito em 14/6/06; publicado na web em 28/11/06

\begin{abstract}
DETERMINATION OF PACLOBUTRAZOL CONCENTRATION BY HIGH PERFORMANCE LIQUID CHROMATOGRAPHY AND SPECTROSCOPY. Paclobutrazol is a plant growth retardant which is used world-wide for increasing the yield of cereal crops. However, this compound remains active in the soil for several years and can severely affect the growth and development of subsequent crops, mainly by reducing vegetative vigor. The aim of this work was to develop and validate methods for the determination of paclobutrazol concentrations by both high performance liquid chromatography and spectroscopy. Both methods were satisfactory and showed appropriately low quantification limits. The determination by spectroscopy has, however, the advantage of being a method significantly less expensive than high performance liquid chromatography.
\end{abstract}

Keywords: paclobutrazol; HPLC; spectroscopy.

\section{INTRODUÇÃO}

Paclobutrazol é um regulador do crescimento de plantas usado no mundo inteiro, tanto para esta finalidade como para aumentar o rendimento de colheitas. Entretanto, é um composto que permanece ativo no solo por vários anos, podendo afetar o crescimento e desenvolvimento de colheitas subseqüentes, principalmente pela redução do vigor vegetativo do solo ${ }^{1}$.

A necessidade de reduzir o impacto ambiental tem despertado o interesse científico para o estudo sobre a biodegradação de tais moléculas. A ação dos microrganismos do solo sobre estas substâncias constitui-se em um importante mecanismo para dissipação da molécula no ambiente ${ }^{2}$. Estudos em laboratório sobre a biodegradação de paclobutrazol, geralmente, são realizados em meios de cultura contendo este composto em concentrações variando entre 0,25 e 1 $\mathrm{g} / \mathrm{L}^{1,3}$, uma vez que a quantidade utilizada no campo varia entre 0,25 e $1,5 \mathrm{~g} / \mathrm{L}$.

A literatura apresenta alguns métodos para a determinação de paclobutrazol ([2RS,3RS]-1-(4-clorofenil)-4,4-dimetil-2-(1H-1,2,4tiazolil-1)pentanol-3), que utilizam cromatografia gasosa $a^{4,5}$ ou cromatografia líquida de alta eficiência (CLAE) acoplada à espectrometria de massa ${ }^{6}$, o que torna a metodologia muito cara.

No presente trabalho foram desenvolvidos dois métodos analíticos, por CLAE e por espectroscopia UV, para a determinação de paclobutrazol em amostras aquosas, como por ex., aquelas provenientes de experimentos de biodegradação deste composto, bem como do produto comercial Cultar $250 \mathrm{SC}$, contendo aproximadamente $250 \mathrm{~g} / \mathrm{L}$ de paclobutrazol.

\section{PARTE EXPERIMENTAL}

\section{Material}

Foi utilizado o padrão de paclobutrazol (PBZ) da Sigma e o produto comercial na forma de uma suspensão de PBZ (Cultar 250 SC). O metanol foi de grau cromatográfico com $99,99 \%$ de pureza

*e-mail: ester_gouveia@yahoo.com.br
(Merck) e a água utilizada foi de grau ultrapuro (Merck, Easy Pure). A amostra aquosa foi um meio de cultura utilizado para investigação da biodegradação de poluentes ${ }^{7}$, preparado com água destilada contendo paclobutrazol (Cultar 250 SC) na concentração de $51 \mathrm{mg} /$ L, quantificado através da curva padrão Sigma.

\section{Preparo das soluções do padrão e das amostras}

A solução do padrão foi preparada dissolvendo-se PBZ (Sigma) em metanol. As soluções de PBZ a partir do Cultar foram preparadas diluindo-se a suspensão em água, com posterior adição de metanol ${ }^{1}$ a $80 \%$ v/v e agitação de 200 rpm. Após 15 min, seguiu-se a centrifugação a $11000 \mathrm{rpm}$ por $5 \mathrm{~min}$. O meio de cultura utilizado como amostra foi fortificado com $51 \mathrm{mg} / \mathrm{L}$ de paclobutrazol, utilizando-se o Cultar, antes da adição de metanol a $80 \%$ v/v. O procedimento utilizado para o preparo da amostra fortificada foi o mesmo usado na preparação da solução de PBZ, a partir do Cultar 250 SC.

\section{Equipamentos}

Na avaliação do espectro de absorção ultravioleta de paclobutrazol, bem como na quantificação por espectroscopia, foi utilizado um espectrofotômetro com detecção por arranjo de diodo (Agilent, modelo 8453). Para a quantificação de paclobutrazol por cromatografia líquida de alta eficiência, foi utilizado um cromatógrafo da Agilent (modelo, 1100) constituído de bomba quaternária, injetor manual, degaseificador e detector espectrofotométrico de absorção no UV/ Vis, de comprimento de onda variável. A coluna utilizada foi ODS, 4,6 x $250 \mathrm{~mm} \times 5 \mu \mathrm{m}$ (Beckman Ultrasphere) e as condições de operação foram fase móvel água:metanol (10:90, v/v), eluição isocrática e vazão de $0,4 \mathrm{~mL} / \mathrm{min}$.

\section{Validação dos métodos}

A validação dos métodos $^{8}$ propostos foi obtida por meio da avaliação dos parâmetros de seletividade, linearidade, precisão, robustez e recuperação, para o método cromatográfico e para o método espectroscópico, utilizando os programas Microsoft Office Excel 2003 e Microcal Origin 6.0. 


\section{RESULTADOS E DISCUSSÃO}

\section{Seletividade}

A farmacopéia americana define a seletividade de um método analítico como sua habilidade em medir, de forma exata, um analito na presença de interferências, as quais se espera que estejam presentes na matriz da amostra ${ }^{8}$. Em geral, uma forma simples de verificar a seletividade de um método cromatográfico é observar a presença de picos na região do tempo de retenção do analito de interesse, injetando-se um branco obtido com a mesma matriz a ser analisada. Nesse caso, devem-se empregar várias amostras, e a ausência de picos próximos ao tempo de retenção do analito de interesse deve ser observada ${ }^{8}$.

O tempo de retenção do padrão de PBZ (Sigma) foi de cerca de 9 min. Para avaliar a seletividade foi injetada uma amostra do branco, isto é, o meio de cultura sem a adição de PBZ. O branco foi injetado quatro vezes e não foi registrado pico durante toda a corrida cromatográfica. O método cromatográfico foi, portanto, considerado seletivo.

Também foi avaliado o espectro de absorção ultravioleta do padrão e do meio de cultura não contendo paclobutrazol (branco), para a avaliação da seletividade pelo método espectroscópico. O método espectroscópico também foi seletivo para a detecção de paclobutrazol.

\section{Linearidade}

A linearidade é a resposta obtida em função da concentração do analito, a qual deve ser estudada em um intervalo de concentração apropriado $^{8,9}$. A faixa linear de detecção que obedece a Lei de Beer é dependente do composto analisado e do tipo de detector utilizado. A linearidade foi determinada pelo coeficiente de correlação (R), obtido pelo gráfico relacionado à resposta do equipamento em função de várias concentrações do analito. O número mínimo de pontos geralmente aceito nos gráficos de calibração varia entre 5 e 6 pontos $^{8}$. As equações da reta são descritas pelas Equações (1) e (2), para o método cromatográfico e espectroscópico, respectivamente, utilizando 5 pontos.

Método cromatográfico

$H(m A u)=3,5 \cdot P B Z(m g / L)+1,2$

$R=0,983$

Método espectroscópico

$A B S(A u)=0,04 \cdot P B Z(m g / L)+0,2$

$R=0,951$

onde $H$ é a resposta do detector relacionada à altura do pico cromatográfico e $A$ é a resposta do espectrofotômetro; ambas as medidas têm unidades de absorvância. Foi observada linearidade na faixa entre 1 e $10 \mathrm{mg} / \mathrm{L}$ para ambos os métodos analíticos.

\section{Precisão}

Para avaliação da repetibilidade do método cromatográfico, uma mesma amostra do padrão de concentração conhecida foi injetada sete vezes pelo mesmo operador, nas mesmas condições de operação e no mesmo dia. A média, o desvio padrão e o desvio padrão relativo das medidas do tempo de retenção e da altura dos picos são apresentados na Tabela 1.

A reprodutibilidade do método cromatográfico também foi avaliada através de sete injeções da mesma amostra do padrão, realizadas por dois operadores, em dois dias diferentes. A Tabela 2 apresenta a
Tabela 1. Repetibilidade do método cromatográfico para a determinação de PBZ

\begin{tabular}{lcc}
\hline Parâmetro & Tempo de retenção & Altura \\
\hline Média & $8,9 \mathrm{~min}$ & $21 \mathrm{mAu}$ \\
Desvio Padrão & $0,0 \mathrm{~min}$ & $1 \mathrm{mAu}$ \\
Desvio Padrão Relativo & $0,0 \%$ & $5 \%$ \\
\hline
\end{tabular}

Tabela 2. Reprodutibilidade do método cromatográfico para a determinação de PBZ

\begin{tabular}{lcccc}
\hline Analista & \multicolumn{2}{c}{ A } & \multicolumn{2}{c}{ B } \\
Dia & 1 & 2 & 1 & 2 \\
\hline Média (mAu) & 21,2 & 21,3 & 21,4 & 20,6 \\
Desvio Padrão (mAu) & 0,5 & 0,1 & 0,5 & 0,7 \\
Desvio Padrão Relativo (\%) & 2 & 0,7 & 2 & 3
\end{tabular}

média, o desvio padrão e o desvio padrão relativo das medidas das alturas dos picos após injeção pelo operador A ou B, no dia 1 ou 2.

A repetibilidade do método espectroscópico foi avaliada, pelo mesmo operador e no mesmo dia, após sete leituras da absorvância de uma mesma amostra do padrão de concentração conhecida. A Tabela 3 apresenta a média, o desvio padrão e o desvio padrão relativo das leituras da absorvância.

Tabela 3. Repetibilidade do método espectroscópico para a determinação de PBZ

\begin{tabular}{lc}
\hline Parâmetro & Absorvância $(221 \mathrm{~nm})$ \\
\hline Média $(\mathrm{Au})$ & 0,22 \\
Desvio Padrão $(\mathrm{Au})$ & 0,0 \\
Desvio Padrão Relativo $(\%)$ & 4 \\
\hline
\end{tabular}

\section{Robustez}

O conceito de robustez de um método analítico é definido como a capacidade de manter-se inalterado em pequenas variações nos parâmetros do método ${ }^{8,9}$. Para avaliar a robustez do método cromatográfico para determinação do paclobutrazol, foram utilizadas duas formas de preparação da fase móvel, isto é, utilizando-se uma proveta e permitindo-se que a mistura de metanol e água, na proporção de 9:1 fosse realizada pela bomba quaternária do sistema cromatográfico (HPLC). A Tabela 4 apresenta a média, o desvio padrão e o desvio padrão relativo das medidas das alturas dos picos obtidos após sete injeções utilizando-se as duas formas de preparação da fase móvel.

Tabela 4. Robustez do método cromatográfico para a determinação de PBZ

\begin{tabular}{lcc}
\hline Parâmetro & Proveta & HPLC \\
\hline Média $(\mathrm{mAu})$ & 22,5 & 21,2 \\
Desvio Padrão $(\mathrm{mAu})$ & 0,3 & 0,3 \\
Desvio Padrão Relativo $(\%)$ & 1 & 2 \\
\hline
\end{tabular}

Na avaliação da robustez do método espectroscópico foram utilizados na preparação da amostra padrão, metanol a 80 e a $100 \%$ v/v. A Tabela 5 apresenta a média, o desvio padrão e o desvio padrão relativo das medidas das absorvâncias obtidas de cinco leituras da amostra utilizando-se as duas formas de preparação. 
Tabela 5. Robustez do método espectroscópico para a determinação de PBZ

\begin{tabular}{lcc}
\hline Parâmetro & $\begin{array}{c}\text { Metanol } \\
(80 \% \text { v/v })\end{array}$ & $\begin{array}{c}\text { Metanol } \\
(100 \% \text { v/v })\end{array}$ \\
\hline Média (Au) & 0,22 & 0,29 \\
Desvio Padrão (Au) & 0,0 & 0,0 \\
Desvio Padrão Relativo (\%) & 4 & 3 \\
\hline
\end{tabular}

\section{Recuperação}

A recuperação é uma medida da eficiência do processo de isolamento do analito de interesse da matriz na qual se encontra presente $^{8}$. A recuperação é determinada pela Equação (3):

$R=\frac{\text { valor obtido }}{\text { valor adicionado }} \times 100$

Este parâmetro foi obtido adicionando-se volumes conhecidos do Cultar 250 SC à matriz de interesse, isto é, o meio de cultura mineral, isento de PBZ, para a obtenção de diferentes concentrações de PBZ, considerando-se a quantificação do Cultar utilizandose a curva de calibração do padrão (Sigma). Foi realizada a preparação da amostra para análise, adicionando-se metanol e utilizando-se as mesmas condições da solução padrão. $\mathrm{O}$ valor do analito foi então determinado também nas mesmas condições cromatográficas e espectroscópicas da solução do padrão. Na maioria dos procedimentos analíticos de validação, valores de recuperação dentro da faixa $70-120 \%$ são aceitos ${ }^{8}$.

A Tabela 6 apresenta os resultados referentes aos percentuais de recuperação de paclobutrazol utilizando os métodos cromatográfico e espectroscópico.
Tabela 6. Recuperação de PBZ utilizando ambos os métodos

\begin{tabular}{lccc}
\hline Método & $\begin{array}{c}\text { PBZ (Cultar) } \\
\text { adicionado } \\
(\mathrm{mg} / \mathrm{L})\end{array}$ & $\begin{array}{c}\text { Concentração } \\
\text { recuperada } \\
(\mathrm{mg} / \mathrm{L})\end{array}$ & $\begin{array}{c}\text { Recuperação } \\
(\%)\end{array}$ \\
\hline CLAE & $\begin{array}{c}1145 \\
1044^{*}\end{array}$ & 91 \\
Espectroscopia & 999 & $999^{* *}$ & 100 \\
\hline
\end{tabular}

*média de duas repetições; **média de quatro repetições

\section{CONCLUSÕES}

Os métodos analíticos propostos para detecção e quantificação de paclobutrazol por cromatografia líquida de alta eficiência e por espectroscopia UV são específicos e lineares na faixa de 1 a $10 \mathrm{mg} /$ L. Ambos os métodos são adequados para avaliação de amostras aquosas que contenham paclobutrazol. O método espectroscópico, entretanto, quando comparado ao método cromatográfico, apresentou-se tão eficiente quanto, sendo, portanto, uma alternativa viável para determinação de paclobutrazol em amostras aquosas, diminuindo significativamente o custo da análise.

\section{REFERÊNCIAS}

1. Jackson, M. J.; Line, M. A.; Hasan, O.; Soil Biol. Biochem. 1996, 28, 1265.

2. Araújo, A. S. F.; Monteiro, R. T. R.; Abarkeli, R. B.; Chemosphere 2003, $52,799$.

3. Silva, C. M. M. S.; Fay, E. F.; Vieira, R. F.; Pesq. Ag. Bras. 2003, 38, 1223.

4. Singh, V. K.; Bhattacherjee, A. K.; J. Plant. Physiol. 2002, 7, 282.

5. Singh, V. K.; Bhattacherjee, A. K.; Sc. Horticulture 2005, 06, 53.

6. Sannino, A.; Bolzoni, L.; Bandini, M.; J. Chromatogr., A 2004, 1036, 161.

7. Ridgway, H. F.; Safarik, J.; Phipps, D.; Carl, P.; Clark, D.; Appl. Environ. Microb. 1990, 56, 3565.

8. Lanças, M.; Validação de métodos cromatográficos de análise, Ed. Rima: São Paulo, 2004.

9. Snyder, L. R.; Kirkland, J. J.; Glajch, J. L.; Practical HPLC method development, $2^{\text {nd }}$ ed., John Wiley \& Sons, Inc: New York, 1997. 